\title{
On the thermo-flow behavior in a rectangular channel with skewed circular ribs
}

\author{
Ali Khodayari Bavil ${ }^{1, a}$ And Seyed Esmail Razavi ${ }^{2}$ \\ 1 Department of Mechanical Engineering, Urmia University, Urmia, Iran \\ 2 School of Mechanical Engineering, University of Tabriz, Tabriz, Iran
}

Received 4 July 2016, Accepted 13 September 2016

\begin{abstract}
The enhancement of heat transfer by the turbulator ribs in cooling channels causes increases of pressure drop. To achieve high thermal performance, a variety of techniques are employed. This study numerically investigates the heat transfer, fluid flow and thermal performance factor in the rib-roughened straight rectangular channel. The ribs have a circular shape and are mounted on the two opposite walls in a staggered arrangement. Four different rib attack angles of $90^{\circ}, 60^{\circ}, 45^{\circ}$ and $30^{\circ}$ to the main flow direction are treated. The results are obtained at entrance Reynolds number of range $25000-50000$. Air is considered as convective fluid in steady state distribution. The three-dimensional flow is simulated with a two-layer $k-\varepsilon$ turbulence model. The governing equations are solved by a control-volume based procedure using second-order upwind scheme. The computational results are compared with the experimental data under the same conditions. It is found that regarding heat transfer enhancement, circular ribs are in preference to block ones. In addition, the angled ribs could enhance the heat transfer significantly when compared to the ribs in $90^{\circ}$ due to the generation of secondary flows. Concerning thermal performance factor, the optimum rib angle is also proposed for different Reynolds numbers.
\end{abstract}

Key words: CFD / Cooling channel / Circular rib / Turbulence flow / Skewed ribs / Secondary flows

\section{Introduction}

The high thermal performance systems are needed for cooling in many industrial applications such as thermal regenerators, electronic cooling devices, fuel cells, and especially internal cooling system of gas turbine blades. Therefore, several methods have been developed extensively to improve heat transfer in these systems. Attempts have been made to enhance heat transfer by using different roughened surfaces or turbulence promoters such as ribs [1], grooves [2], winglets [3] and baffles [4] in disturbing the flow. The presence of ribs enhances the heat transfer coefficients by perturbing on the hydrodynamic and thermal boundary layers. Downstream of each rib the flow separates, recirculates and impinges the channel wall. The use of ribs raises not only the heat transfer rate but also pressure loss. Therefore, a compromise should be made between the heat transfer and pressure losses.

The effects of geometric parameters such as relative rib height, relative rib pitch, attack angle, duct aspect ratio, rib cross-section geometry, rib arrangement and rib configuration have been widely studied. Wang et al. [5]

\footnotetext{
${ }^{a}$ Corresponding author: khodayari.b@gmail.com
}

carried out experimental studies for rib pitch-to-height ratios varying from 8 to 15 , four different rib shapes and the test Reynolds number 8000 to 20000 . They discerned the best functioned rib shape in terms of heat transfer and friction factor and released comparable data for different cases. Han et al. [6,7] experimentally studied the heat transfer in a square channel with different angled rib arrays on two walls for $P / e=10$ and $e / D=0.0625$. They demonstrated that the angled ribs provided higher heat transfer enhancement in comparison to the continuous ribs and also reported the highest value is at the $60^{\circ}$ orientation amongst the angled ribs. Xie et al. [8] preferred the $v^{2} f$ turbulence model among six different models and numerically studied flow structure and heat transfer in a square passage with six different configurations of truncated ribs.

In most previous studies, the ribs on the two opposite walls arrayed normal to the main flow direction. The authors of [9-11] experimentally studied flow in a rectangular channel at a rib attack angle of $45^{\circ}$. It was shown that at high Reynolds numbers, heat transfer in the channel with straight ribs on the wall could be increased almost twice. Also, it could be increased by the factor of three in the channels with inclined ribs. The authors represented 


\section{Nomenclature}

\begin{tabular}{|llll|}
\hline$D_{h}$ & Hydraulic diameter $[\mathrm{m}]$ & $R e$ & Reynolds number $\left(=\frac{\rho \cdot V \cdot D_{h}}{\mu}=\frac{\dot{m}}{\mu \cdot D_{h}}\right)$ \\
$e$ & Rib height $[\mathrm{m}]$ & $T_{b}$ & Bulk mean temperature of flow $[\mathrm{K}]$ \\
$f$ & Friction factor & $T_{W}$ & Wall temperature $[\mathrm{K}]$ \\
$f_{0}$ & Friction factor of smooth channel & $\mathbf{U}$ & Vector of velocity $\left[\mathrm{m} . \mathrm{s}^{-1}\right]$ \\
$h$ & Heat transfer coefficient $\left[\mathrm{W} /\left(\mathrm{m}^{2} \mathrm{k}\right)\right]$ & $\mathrm{V}$ & Mean flow velocity $\left[\mathrm{m} \cdot \mathrm{s}^{-1}\right]$ \\
$H$ & Channel height $[\mathrm{m}]$ & $\mathrm{W}$ & Channel width $[\mathrm{m}]$ \\
$k$ & Turbulence kinetic energy per unit mass $\left[\mathrm{m}^{2} \cdot \mathrm{s}^{-2}\right]$ & $\varepsilon$ & Turbulence dissipation rate $\left[\mathrm{m}^{2} \cdot \mathrm{s}^{-3}\right]$ \\
$N u$ & Nusselt number & $\rho$ & Fluid density $\left[\mathrm{kg} \cdot \mathrm{m}^{-3}\right]$ \\
$N u_{0}$ & Nusselt number of smooth channel & $\mu$ & Dynamic viscosity $[\mathrm{kg} /(\mathrm{m} . \mathrm{s})]$ \\
$P$ & Rib pitch $[\mathrm{m}]$ & $\mu_{t}$ & Turbulent viscosity $[\mathrm{kg} /(\mathrm{m} . \mathrm{s})]$ \\
$p$ & Thermodynamic pressure $\left[\mathrm{kg} /\left(\mathrm{m} \cdot \mathrm{s}^{2}\right)\right]$ & $\eta$ & Thermal performance factor \\
$\dot{m}$ & Flow rate $[\mathrm{kg} . \mathrm{s}-1]$ & $x, y, z$ & Orthogonal coordinate system $[\mathrm{m}]$ \\
$P r$ & Prandtl number & $\mathrm{A}, \mathrm{B}, \mathrm{C}, \mathrm{D}$ & Different case studies \\
$q "$ & Heat flux $[\mathrm{W} . \mathrm{m}-2]$ & & \\
\hline
\end{tabular}

two main reasons for this heat transfer augmentation. On the one hand it is caused by means of advection in secondary flow at separation zones. On the other hand, an increase in the value of 3D turbulent transfer with additional production of turbulent energy in a thicker shear layer with high velocity gradients brings an additional contribution.

Casarsa et al. [12] experimentally studied the effects of block-ribs on flow field inside a gas turbine trailing edge cooling channel. They reported that under static conditions, despite that the ribs are inclined with respect to the channel radial axis, no guiding effect induced by the ribs takes place and separation behind the obstacles has similar characteristics all along the rib spans. Tanda [13] experimentally studied forced convection heat transfer in a rectangular channel with angled rib turbulators inclined at $45^{\circ}$. The angled ribs were deployed with parallel orientation on one or two surfaces of the channel. The effects of ratio of rib height to hydraulic diameter, rib spacing and rib pitch-to-height ratio $(p / e)$ on the thermal performance were examined. Among the many geometric parameters related to the rib arrangement and configuration, the shape of the rib cross section affects the formation of a separation bubble behind the rib and the amount of turbulent kinetic production; thus, the rib shape is a major factor that determines heat transfer performance of the rib. Moon et al. [14], using SSG Reynolds stress model, numerically evaluated heat transfer and friction loss performances of sixteen crosssectional rib shapes in a rectangular channel. They reported that the performance parameters related to heat transfer and friction factor were strongly dependent on rib cross-sectional shape. Both heat transfer and friction factor performances generally improved as the Reynolds number was increased.

Johnson and Wagner [15, 16] studied experimentally the heat transfer and pressure drop in a square channel with varying Reynolds numbers, coolant-to-wall temperature ratios, radius-to-passage hydraulic diameter ratios and rotation numbers. They used circular ribs in a staggered arrangement and presented the results for ribs that were normal and $45^{\circ}$ angle to the main flow direction.

It is still an interesting issue in the design of coolant channels in gas turbine blades to obtain larger augmentation of heat transfer coefficient with lower friction loss. The aim of present study is the investigation of fluid flow and heat transfer in square cooling channel with two opposite rib-roughened walls. Effects of circular ribs in staggered arrangement inside the channel with different attack angles of $90^{\circ}, 60^{\circ}, 45^{\circ}$ and $30^{\circ}$ to the main flow direction (Cases A, B, C and D, respectively) are studied. All of the numerical calculations are carried out in a turbulent regime with the Reynolds number based on the hydraulic diameter (Re) of 25000 and 50000 . The computational results compared with previous similar studies.

\section{Mathematical formulations}

A three dimensional, turbulent, incompressible, steady flow of Newtonian fluid (air) takes place in channel. The fluid properties are supposed to be constant and applied as a function to computational code. Since two layer turbulence model of $k-\varepsilon$ produces satisfactory results of the mean and turbulence motions [10], it has been utilized in present study.

The channel governed by the incompressible NavierStokes equations, which are written in the Cartesian tensor system as follows.

Continuity equation:

$$
\frac{\partial}{\partial x_{j}}\left(U_{\mathbf{j}}\right)=0
$$

Momentum equation:

$$
\frac{\partial\left(\rho U_{\mathbf{i}} U_{\mathbf{j}}\right)}{\partial x_{j}}=-\frac{\partial P^{\prime}}{\partial x_{i}}+\frac{\partial}{\partial x_{j}}\left[\left(\mu+\mu_{t}\right)\left(\frac{\partial U_{i}}{\partial x_{j}}+\frac{\partial U_{j}}{\partial x_{i}}\right)\right]
$$


where $p^{\prime}$, modified pressure, and $\mu_{t}$, the turbulence viscosity, are defined as:

$$
\begin{aligned}
& p^{\prime}=p+\frac{2}{3} \rho k \\
& \mu_{t}=C_{\mu} \rho \frac{k^{2}}{\varepsilon}
\end{aligned}
$$

The value of $k$ and $\varepsilon$ come directly from the differential transport equations for the turbulence kinetic energy and turbulence dissipation rate:

$$
\begin{aligned}
\frac{\partial}{\partial x_{j}}\left(\rho U_{j} k\right) & =\frac{\partial}{\partial x_{j}}\left[\left(\mu+\frac{\mu_{t}}{\sigma_{k}}\right) \frac{\partial k}{\partial x_{j}}\right] \\
& +P_{k}-\rho \varepsilon+P_{k b} \\
\frac{\partial}{\partial x_{j}}\left(\rho U_{j} \varepsilon\right) & =\frac{\partial}{\partial x_{j}}\left[\left(\mu+\frac{\mu_{t}}{\sigma_{\varepsilon}}\right) \frac{\partial \varepsilon}{\partial x_{j}}\right] \\
& +\frac{\varepsilon}{k}\left(C_{\varepsilon 1} P_{k}-C_{\varepsilon 2} \rho \varepsilon+C_{\varepsilon 1} P_{\varepsilon b}\right)
\end{aligned}
$$

$P_{k b}$ and $P_{\varepsilon b}$ represent the influence of the buoyancy forces, which are described for fully buoyancy model as:

$$
\begin{aligned}
P_{k b} & =-\frac{\mu_{t}}{\rho} g_{i} \frac{\partial \rho}{\partial x_{i}} \\
P_{\varepsilon b} & =\max \left[0, P_{k b}\right]
\end{aligned}
$$

$P_{k}$, the turbulence production due to viscous forces, is modeled using:

$$
P_{k}=\mu_{t}\left(\frac{\partial U_{i}}{\partial x_{j}}+\frac{\partial U_{j}}{\partial x_{i}}\right) \frac{\partial U_{i}}{\partial x_{j}}
$$

The constants used in the equations are specified as:

$$
C_{\mu}=0.09, \sigma_{k}=1, \sigma_{\varepsilon}=1.3, C_{\varepsilon 1}=1.44, C_{\varepsilon 2}=1.92
$$

The governing equations are solved using control volume approach and the SIMPLE (Semi Implicit Method for Pressure-Linked Equations) algorithm. The differential equations were discretized by the second-order upwind scheme. The solutions are considered to be converged when the normalized residual values are within $10^{-6}$ for all variables.

\subsection{Flow configuration}

The geometric parameters of interest are shown in Figure 1 . The passage is a horizontal 4-cell square channel roughened by circular ribs with different attack angles of $90^{\circ}, 60^{\circ}, 45^{\circ}$ and $30^{\circ}$ to the main flow direction on the upper and lower channel walls in a staggered arrangement. The top views of the lower surface for the different cases are shown in Figure 2. The rib height to hydraulic diameter ratio is $e / D=0.1$ and the rib pitch to height ratio is $P / e=10$.

To investigate the flow under fully developed conditions, a uniform velocity profile was specified at the inlet

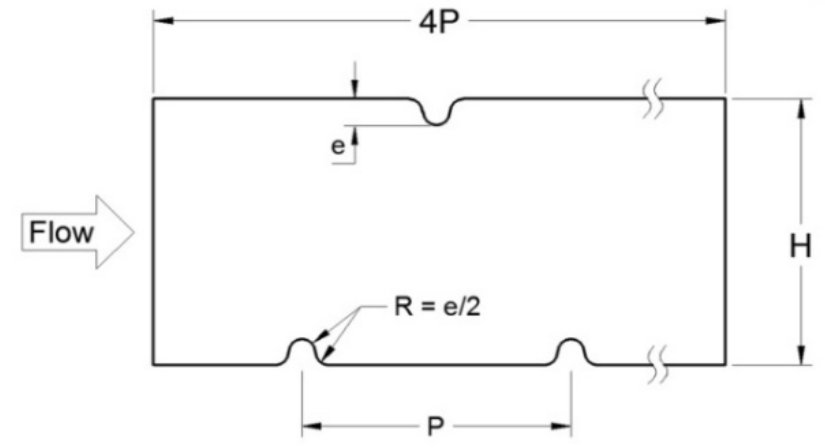

(a)

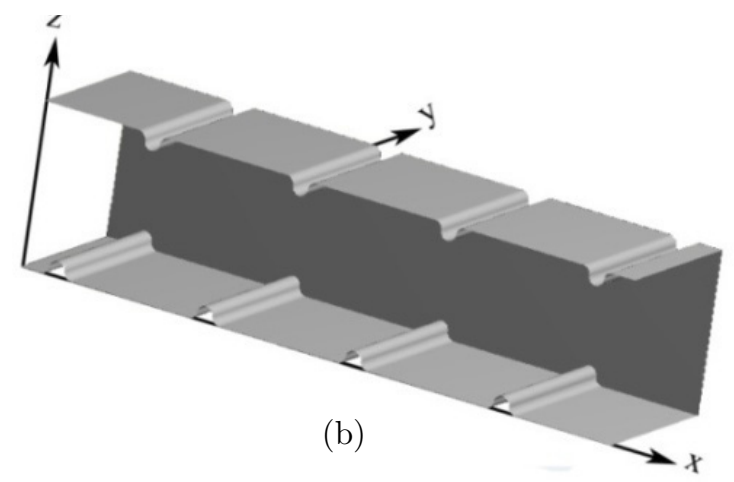

Fig. 1. Staggered arrangement of studied geometry: (a) Geometric parameters; (b) Ribs on upper and lower walls of Case study A.

of the separate channel with the length of $10 D_{h}$ and uniform entrance temperature of $T_{i n}$. Then the results in outlet are governed to the different case studies. The pressure is specified at the outlet and all other thermodynamically parameters are extrapolated. The non-slip conditions are prescribed for each wall and temperature of the side walls was maintained at $T_{w}$.

\subsubsection{Grid characteristics}

The mesh quality has an important impact on the accuracy of the numerical results. According to circular shapes of the ribs, it is unavoidable to use both structural and unstructured grids. For each case of different system geometry, a computational mesh is built of structured grids clustered in the region of ribs, leading and trailing surfaces to define flow parameters more precisely. Therewith, unstructured grids consisting of tetrahedral cells are applied in the inmost regions as shown in Figure 3a. For a grid-independence analysis, minimum and maximum cell sizes maintained at 0.0001 meter and 0.001 meter respectively. Four different grid systems processed of different growth rate of cells sizes from minimum to maximum, representing the different $\mathrm{y}^{+}$values of nearwall nodes, have been tested on base case of A. Figure 3b illustrates the effects of different grid systems on calculated Nusselt number. The mesh independence tests for more than 700000 cells have not yielded any significant 

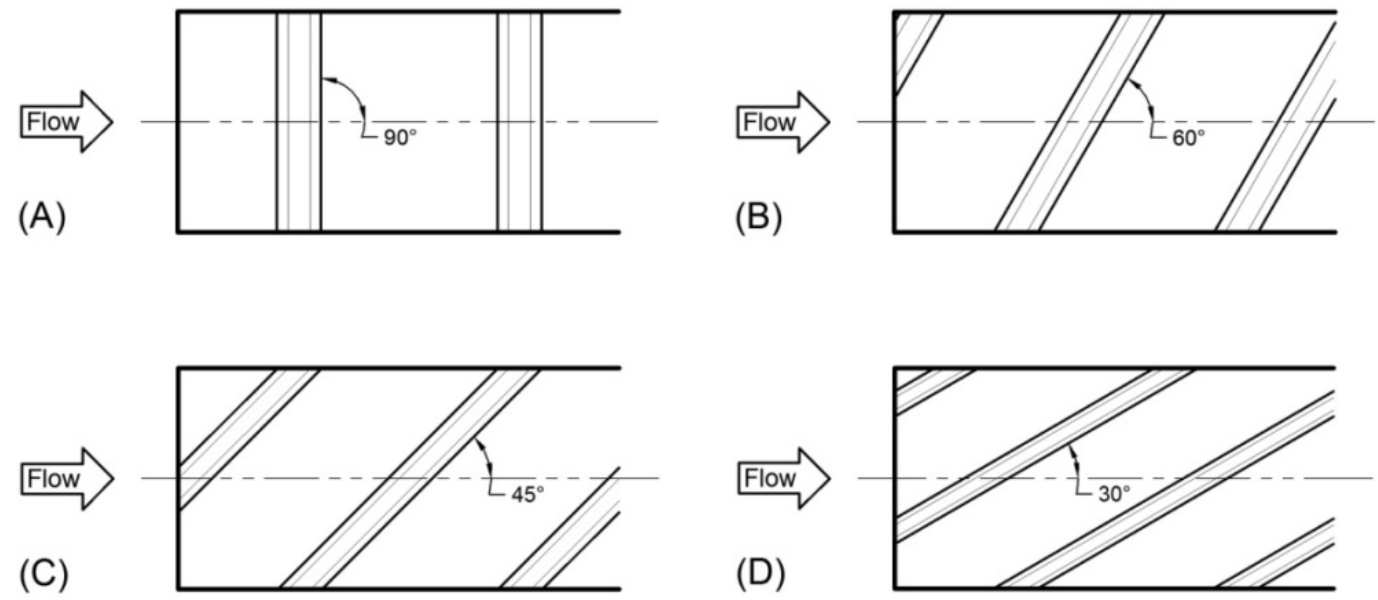

Fig. 2. Rib configuration on lower surface for different cases A, B, C and D.

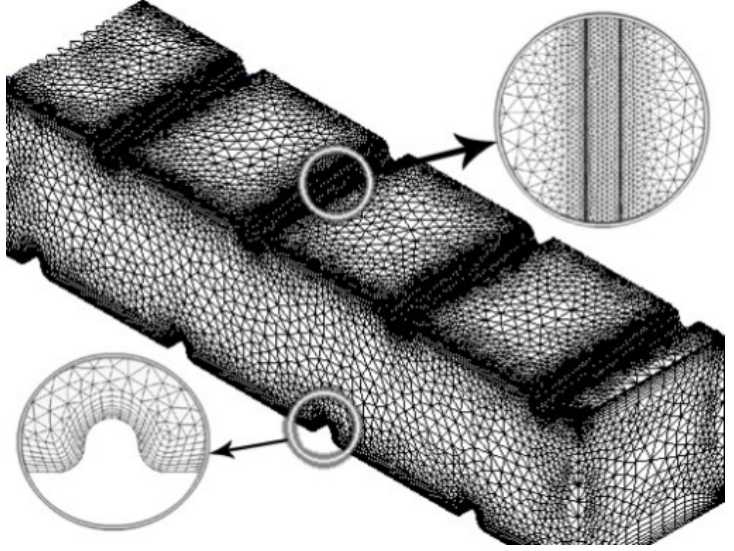

(a)

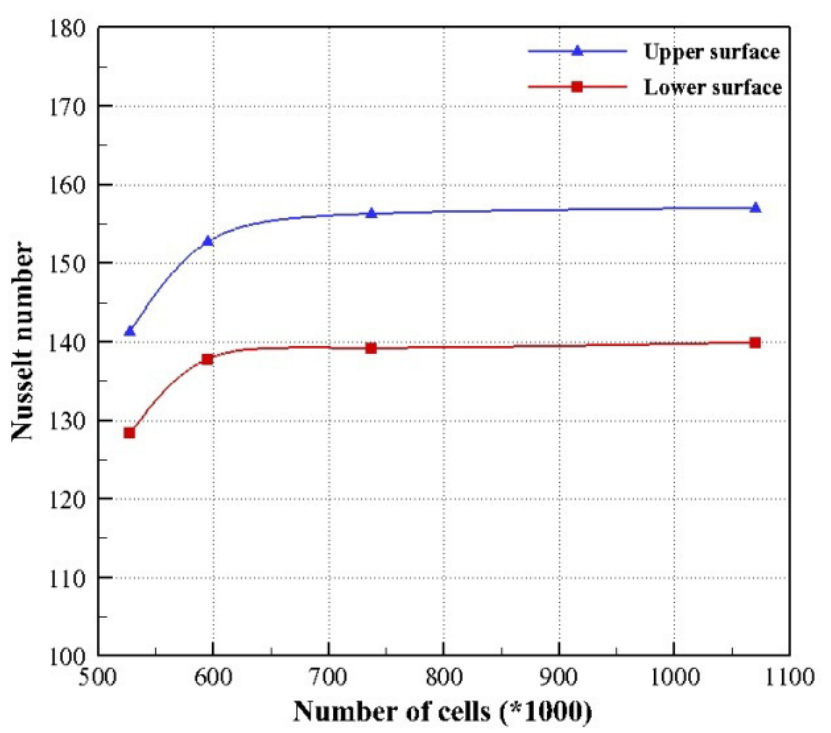

(b)

Fig. 3. Computational grid: (a) Details of grid, (b) Grid independence study. differences with increasing number of elements. Therefore, to keep a balance between computational economy and prediction accuracy, 730000 cells is used for the computations in all study cases.

\subsection{Code validations}

To validate the solutions, comparisons with the published results of Wagner et al. [15] are made for leading (upper) and trailing (lower) surfaces with normal ribs. As shown in Figures $4 \mathrm{a}$ and $4 \mathrm{~b}$, which represents Nusselt number against Reynolds number on the upper and lower surfaces of the channel with normal ribs, good agreement is perceived between the two studies.

\subsection{Parameter definition and data reduction}

Parameters of interest in the present work are defined in below. The heat transfer is obtained by calculating the Nusselt number with the following equation:

$$
N u=\frac{q^{\prime \prime}}{\left(T_{w}-T_{b}\right)} \cdot \frac{D_{h}}{k}
$$

where $T_{w}$ is the surface temperature and $T_{b}$ is the bulk fluid temperature. To describe the augmentation rate of heat transfer caused by the ribs, $N u_{0}$ obtained from the Dittus-Boelter correlation [17] for the fully developed turbulent flow in a smooth channel, is used:

$$
N u_{0}=0.023 \times \operatorname{Re}^{0.8} \times \operatorname{Pr}^{0.4}
$$

The dimensionless pressure drop (friction factor) over the entire test channel is calculated based on the pressure drop $(\Delta P)$ across the entire test channel of length $L$ with the mean flow velocity $(V)$ evaluated from the inlet of the test channel with Darcy-Weicbach factor as:

$$
f=\frac{\Delta P}{4 \times\left(\frac{L}{D_{h}}\right) \times\left(\frac{1}{2} \rho \cdot V^{2}\right)}
$$




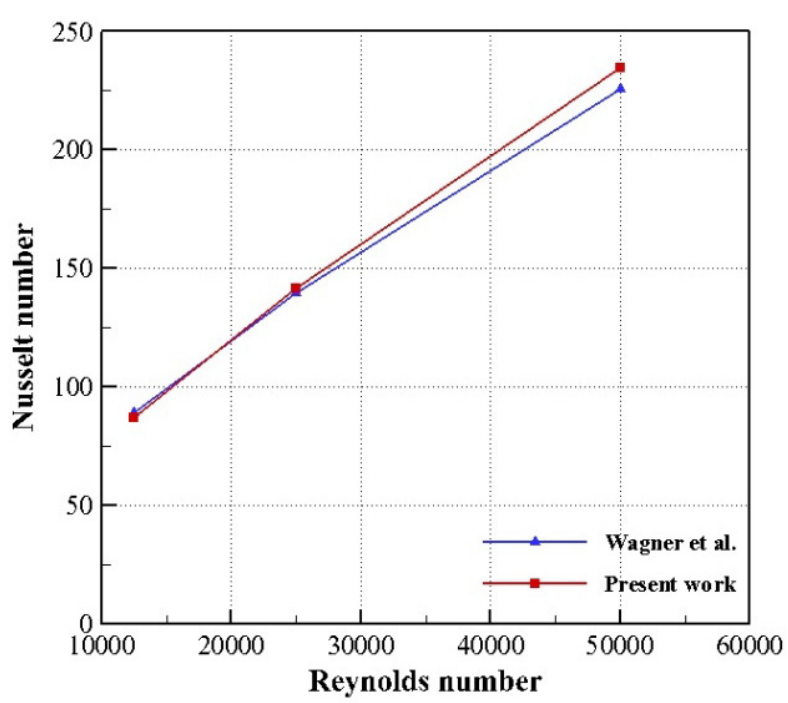

(a)

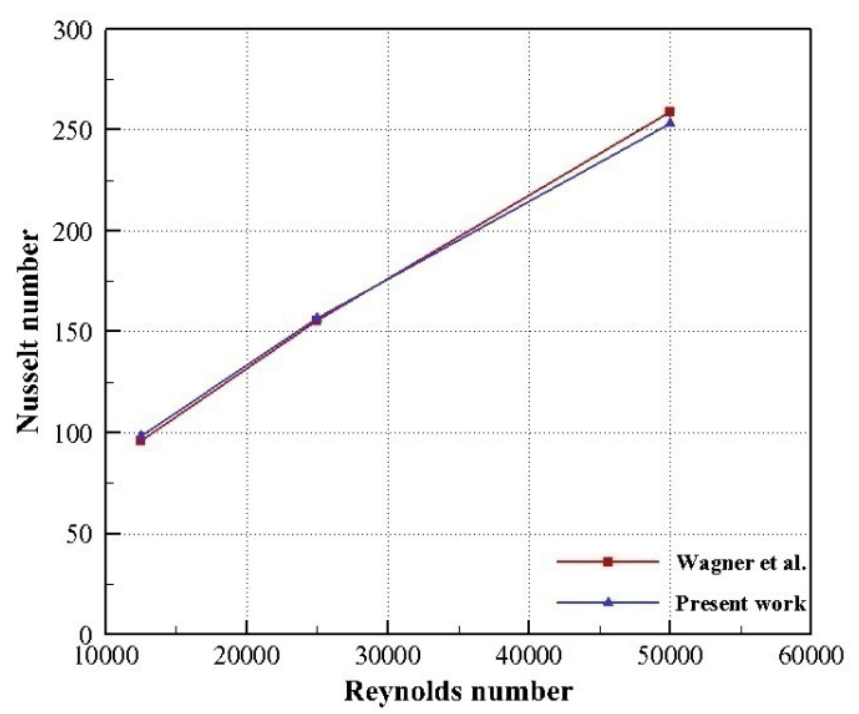

(b)

Fig. 4. Validation of present study concerning Nusselt number for different Reynols number on: (a) leading (upper) surface, (b) trailing (lower) surface.

The normalizing relation for the friction factor is [17]:

$$
f_{0}=0.046 \times R e^{-0.2}
$$

To evaluate integrally effects of the thermal and fluid performances of the ribbed channel, the thermal performance factor $(\eta)$ is defined as below:

$$
\eta=\left(\frac{N u}{N u_{0}}\right)\left(\frac{f}{f_{0}}\right)^{1 / 3}
$$

where $N u$ is the averaged Nusselt number over top and bottom surfaces and $f$ is the friction factor.

\section{Results and discussion}

Prior to presenting detailed flow patterns in different cases, it is helpful to display some flow features of normal rib to show effects of circular ribs in comparison with rectangular (block) ribs. As shown in Figure 5, a big separation bubble is observed in the vicinity of block ribs due to flow separation and reattachment [18]. The most striking feature is the formation of a large recirculation bubble downstream of the rib. In comparison to the circular ribs, another small separation bubble occurs as a result of the strong adverse pressure gradients upstream of the block rib. It is observed that circular rib induces flow reattachment on the roughened surface earlier than for the block rib and decreases separation length approximately $20 \%$, as shown in Figure 5. In addition, it is observed that with circular shapes, there is no other separation bubble in the upstream and the streamlines adopted with presence of rib.

To show effects of flow accommodation to the rib shape and disappearance of small separation bubbles nearby the ribs, comparison of experimental data extracted from [5] for block ribs with calculated local normalized Nusselt number on midline of the channel between the third and forth ribs, are reported in Figure 6. Considering these experimental values on the lower surface of the channel, it confirms that about $25 \%$ improvement of heat transfer for circular ribs in comparison to block ribs.

Distributions of normalized Nusselt on leading (upper) and trailing (lower) surfaces with $R e=25000$ and 50000 in the midline of the channel, where $Y / D=0.5$, are shown in Figures $7 \mathrm{a}$ and $7 \mathrm{~b}$ for rib attack angles of $90^{\circ}$ and $45^{\circ}$, respectively. Case $\mathrm{C}$ is depicted as representative of skewed ribs to compare with normal ribs. Although it is predictable to increase Nusselt number by growing the Reynolds number, normalized Nusselt numbers are decreased in both cases. On the other hand, growing Reynold number creates significant variant on distribution of normalized Nusselt number through the ribs. It is noticed that peak points of normalized Nusselt number identifiable on top of the ribs, reduce in skewed ones and observed less sharpness in vicinity of ribs. Due to generation of secondary flows in cross section of oriented ribs, flows are intensely turbulated and therefore high rate of heat transfer is predicting. In addition, the minimum rate of normalized Nusselt number happens in downstream of the ribs, where separation bubble generates.

Figure 8 illustrate top views of the normalized Nusselt number's contours on the leading and trailing surfaces of the channel for a Reynolds number equal to 25000 , where $X / D=1$ to 3 . The normalized Nusselt number are generally higher than 1 , consequently added ribs, regardless to their direction against main flow, could increase heat transfer coefficient. In addition, the normalized Nusselt numbers of Cases B and C are generally larger those of Cases A and D. It is expected to have larger heat transfer with skewed ribs as explained before, but in Case $\mathrm{D}$, the generation of strong secondary flows and bigger vortexes in the cross section of the channel cause lower 


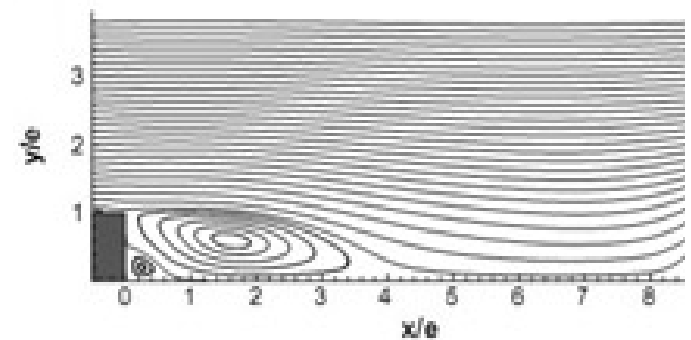

(a)

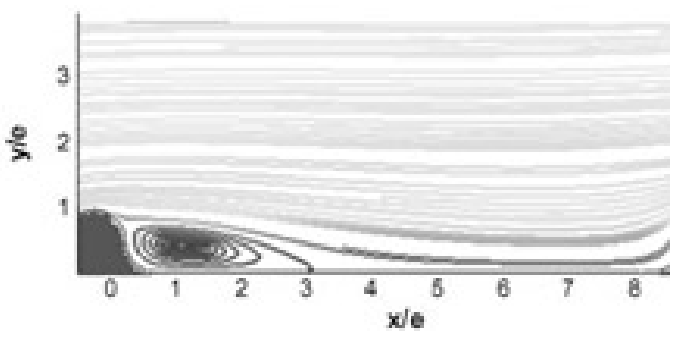

(b)

Fig. 5. Comparison of streamlines in vicinity of ribs on lower surface (a) Lee et al. [18], (b) present study.

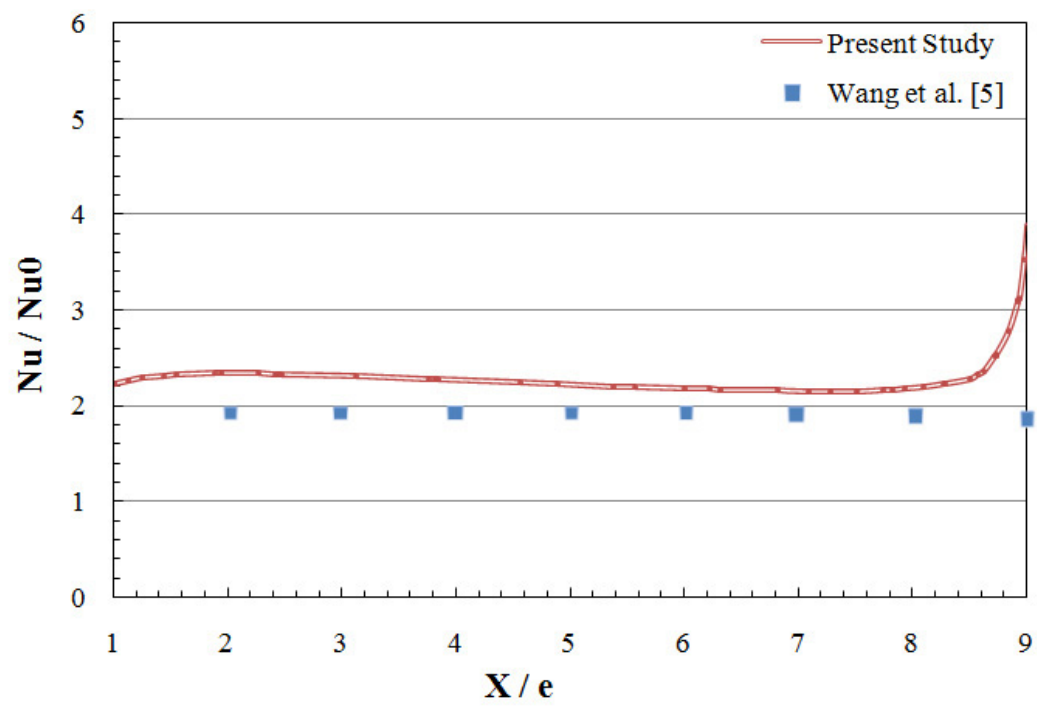

Fig. 6. Comparison of local heat transfer for normal ribs (Case A).

normalized Nusselt number. As contours in Figure 8 show, in all cases the maximum normalized Nusselt number occurs at the back of the ribs, especially in Case A, where flow contacts directly to the ribs and stagnation point can be recognized. On the other hand, the normalized Nusselt numbers in Case A distribute monotonously on the upper and lower surfaces between the ribs, while varied amounts are observe by tilting the ribs. It is more likely to have higher heat transfer rate on lower surfaces according to wide prevalence of higher normalized Nusselt numbers which is more considerable in skewed ribs.

Generation of secondary cross sectional flow is an important aspect of duct flows which has a large impact on heat transfer augmentation. This phenomenon, induced by adverse pressure gradients, is observed inside the smooth channels, but it is more complicated and significant in ribbed channels. Figure 9 shows the vectors of velocity in cross section of the channel. In order to reduce entrance effects and present accurate results, third cell of the passage is considered where $X / D=2$ to 3 . These flows are driven by the periodic flow disturbances caused by the ribs and the junction flow where the rib meets the side wall [19]. These secondary flows in the cross- section of the duct occur due to the combined effect of the rib and the side walls. Flows encountering to ribs, cause to generating of unsteady vortical structures. These vortexes are pushed toward side walls by the mean flow of duct, which is much stronger in skewed ribs; due to direct drawing of flow by oriented ribs. The side walls transmit these flows upward and in top of the channel, where these two streams approaches, flows govern to the middle of the channel. In the vicinity of the rib and side wall junction; strong localized unsteady vertical structures are generated. Lateral impingement velocities reach as high as $30 \%$ of the mean stream-wise velocity in this region for normal ribs [1]. This manner of flow is more saleint in skewed ribs as shown in Figures 9b-9d for Cases B, C and $\mathrm{D}$, respectively.

As an overall assessment for each cases, thermal performance factor $(\eta)$ versus different rib angles are illustrated in Figure 10 for Reynolds number of 25000 and 50 000. Increasing Reynolds number decreases total thermal performance factor in channel for each cases, and also decreases the effects of rib angles on thermal performance. It is noticed that increasing Reynolds number has less effects on Case D in comparison to other cases. In addition, inclined ribs (Cases $\mathrm{B}, \mathrm{C}$ and $\mathrm{D}$ ), which provide stronger secondary flows, increase the thermal performance factor in comparison to normal ribs (Case A). On the other hand, as shown in Figure 10, low angles 


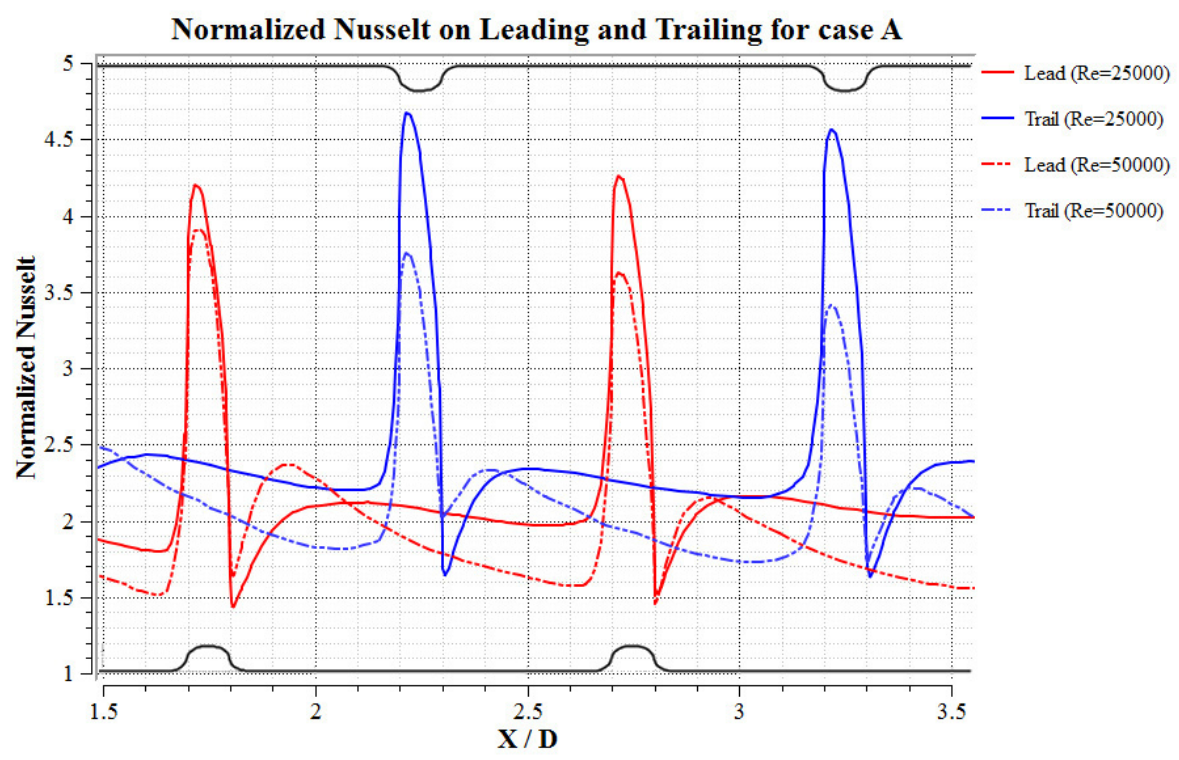

(a)

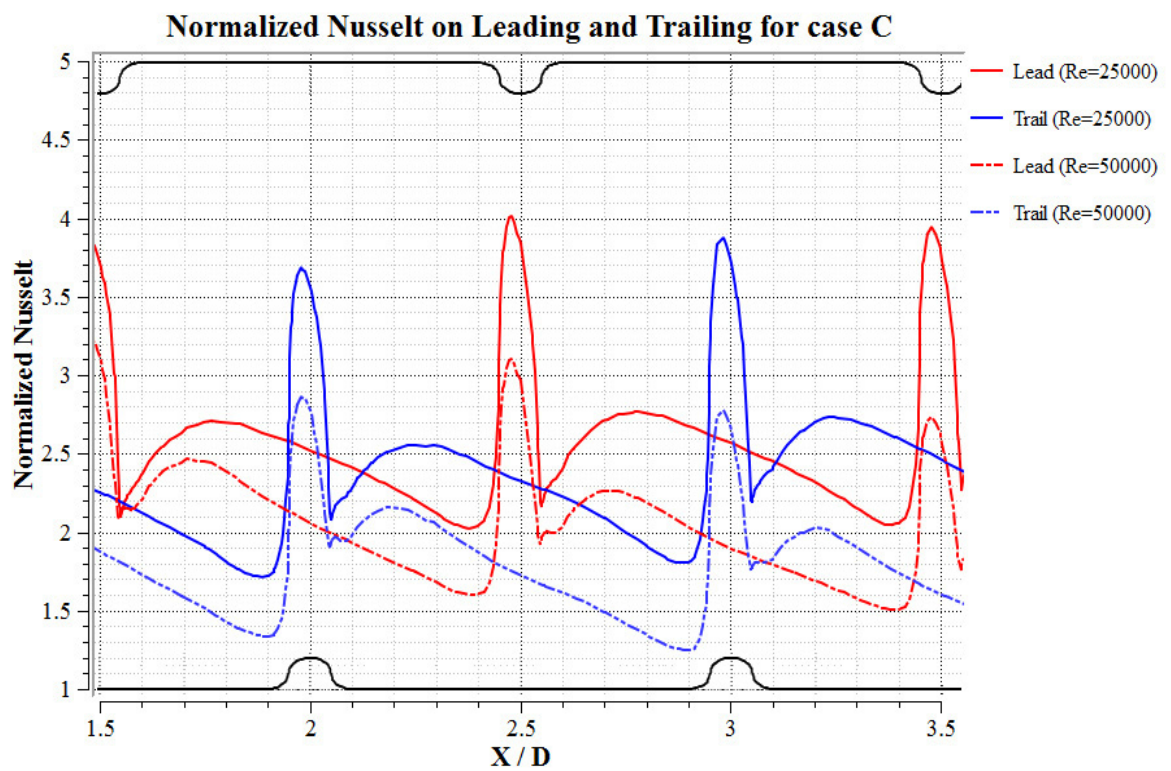

(b)

Fig. 7. Distribution of normalized Nusselt number on leading and trailing surfaces: (a) Case A (b) Case C.

(case D) by generating strong cross sectional flows raise rate of pressure drop and therefore, leads lower amount of total thermal performance. These effects cause to locate the recommended design point between normal ribs and $30^{\circ}$ (Cases A and D). This point tends to move to large rib angles (Case A) by increasing Reynolds number due to remarkable raise in pressure drop.

\section{Conclusions}

The main contribution of this paper is to conduct a detailed numerical study of the fluid flow and heat transfer in the channel with staggered circular ribs. The effects of different rib angles to the main flow direction (four cases) and Reynolds number on the velocity field and the heat transfer are investigated. The following important conclusions can be drawn based on the present study:

Using the circular ribs obliges the streamline to pass smoothly over the ribs. It causes disappearing of the separation bubble behind the circular ribs and also decreases the length of the flow reattachment. Consequently, circular ribs show enhanced heat transfer coefficient in comparison with square ribs (blocks).

The normalized Nusselt number on two roughened walls of channel is presented for $R e=25000-50000$. It is observed that for higher Reynolds number, although peak heat transfer levels decrease, the total heat trans- 

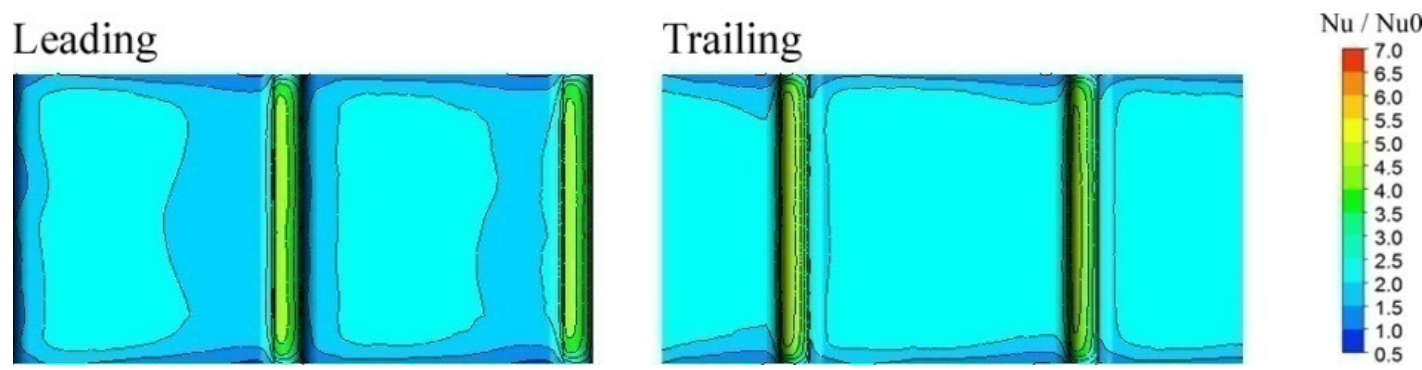

(a)
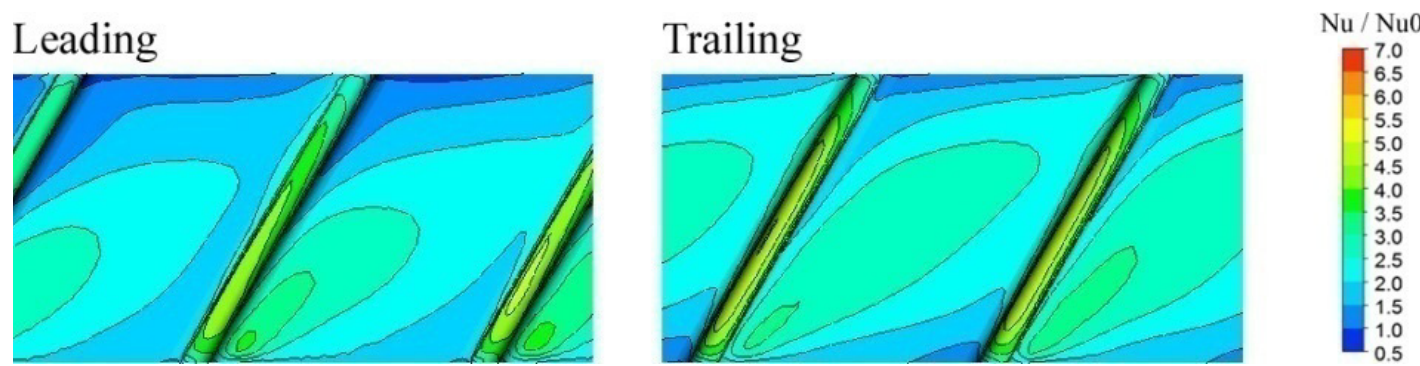

(b)
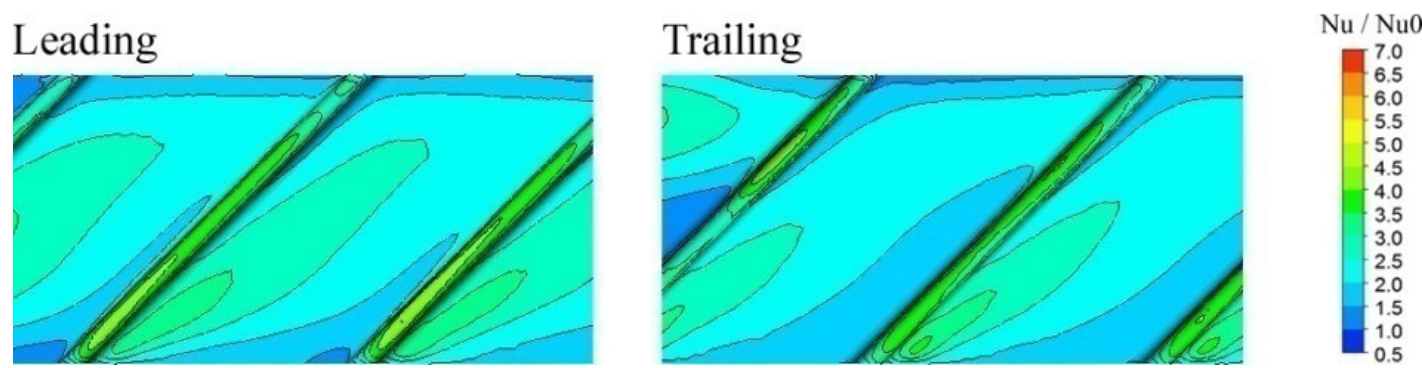

(c)

\section{Leading}

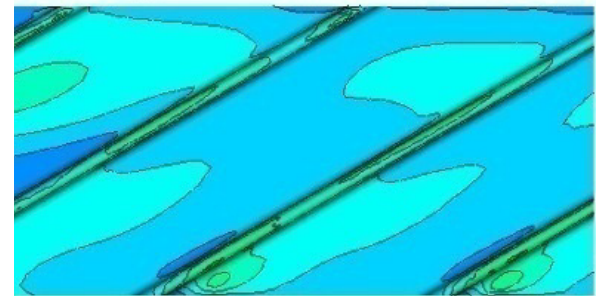

\section{Trailing}

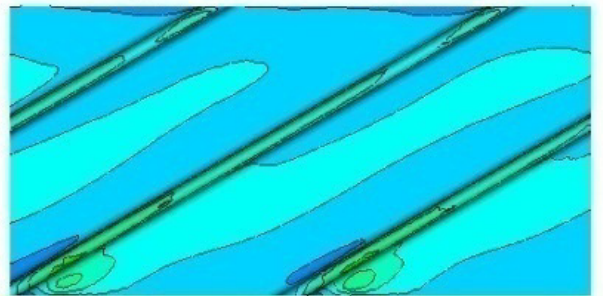

$\mathrm{Nu} / \mathrm{Nu} 0$

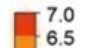

6.5

6.0
5.5

$-5.0$

$-4.5$

3.5

3.0

2.5
2.0

1.5
1.0

0.5

(d)

Fig. 8. Normalized Nusselt distribution on upper and lower surfaces (top view) in the channel for different rib angles: (a) Case A; (b) Case B; (c) Case C; (d) Case D.

fer is augmented through the ribs. In addition, raising Reynolds number disturbs the uniform distribution of the turbulence intensities and significantly leads variant normalized Nusselt number between the ribs.

Distribution of normalized Nusselt number and velocity vectors are presented for different study cases. It shows that normal ribs do not create any significant flow in cross section, whereas skewed ribs governs the flow to the side walls and therefore produces strong cross sectional flows, which alters the distribution of heat transfer and pressure drop.

Skewed ribs provide strong secondary flows and enhance the heat transfer. To consider both effects of heat transfer enhancement and pressure drop in presence of the ribs, thermal performance factor studied and it revealed that varying rib orientation in range of $90^{\circ}$ to $30^{\circ}$ make a peak point for thermal performance factor. The strong influences of the angled ribs induce secondary motions. 
A. Khodayari Bavil and S.E. Razavi: Mechanics \& Industry 18, 225 (2017)

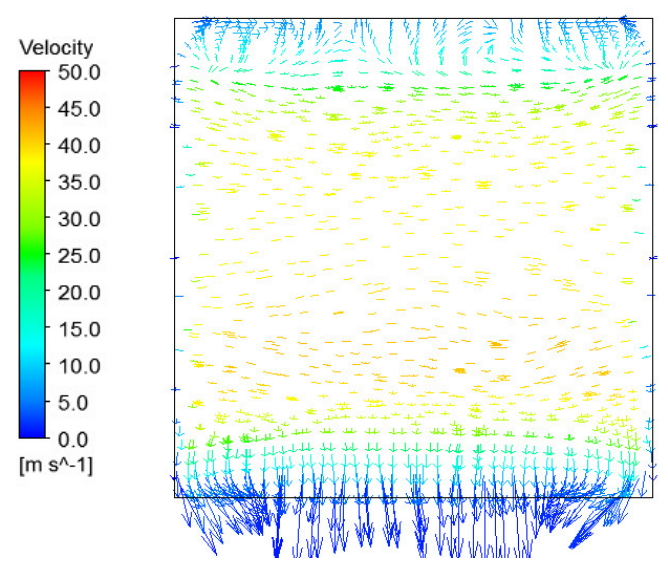

(a)

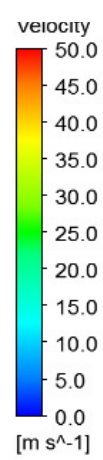

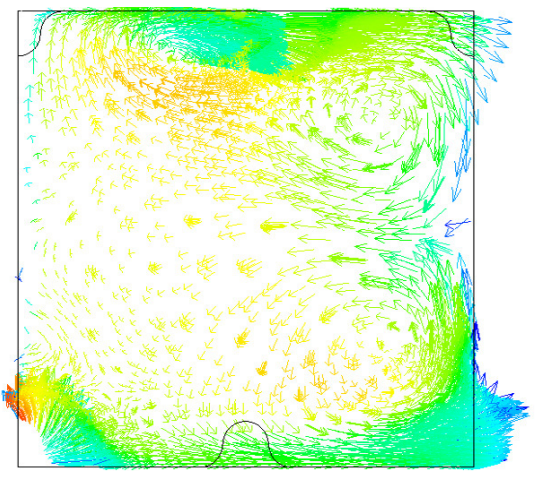

(c)

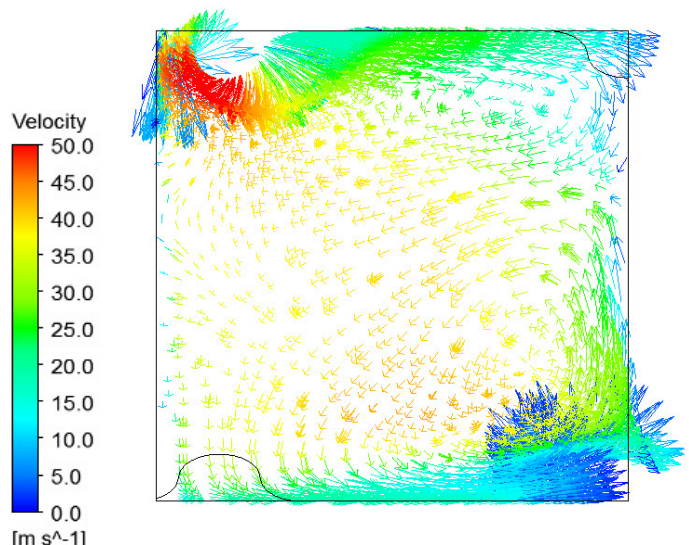

(b)
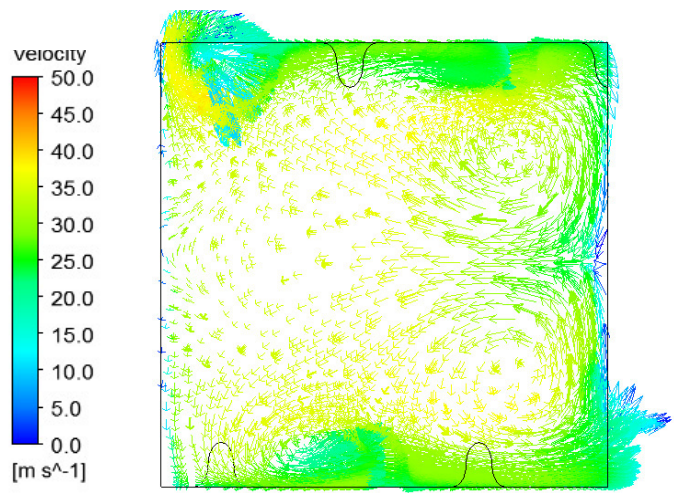

(d)

Fig. 9. Vectors of velocity for $R e=25000$ in $X / D=2.5$ : (a) Case A; (b) Case B; (c) Case C and (d) Case D.

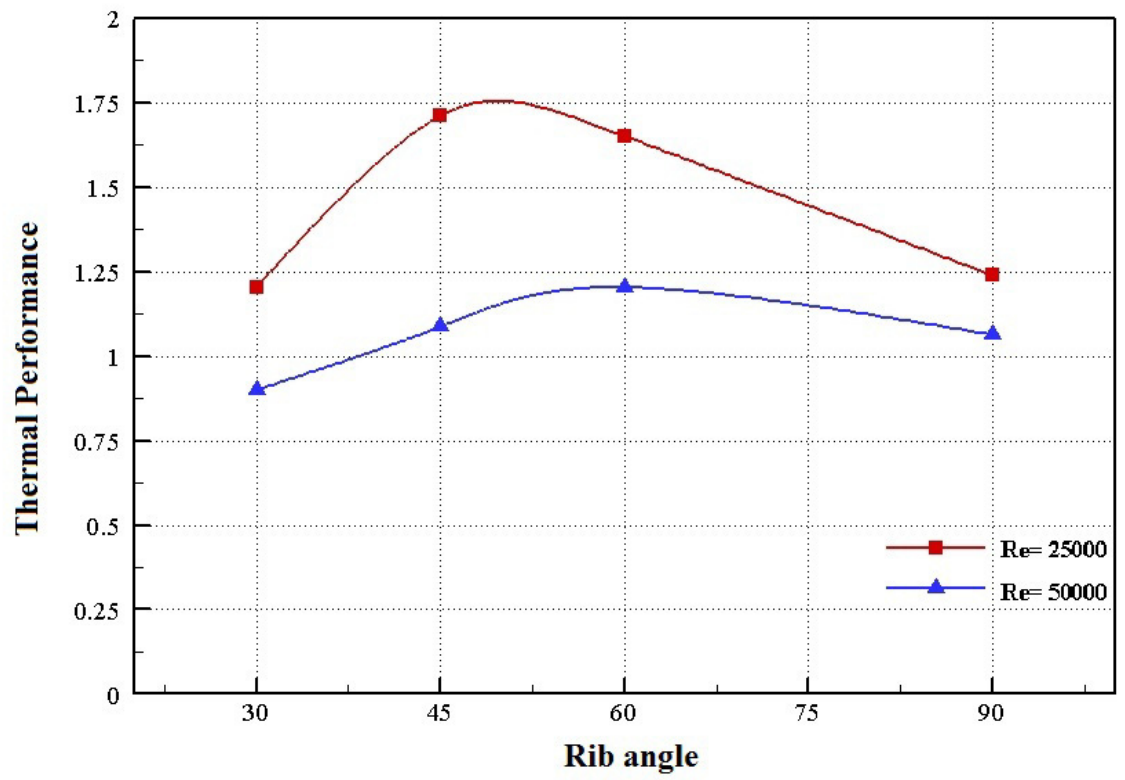

Fig. 10. Thermal performance for different Reynolds numbers versus rib angles. 
Influence of turbulence intensity on the flow and thermal development, leads the optimum design point to locate between rib angles of $45^{\circ}$ and $60^{\circ}$ by raising Reynolds number.

\section{References}

[1] E.A. Sewall, D.K. Tafti, A.B. Graham, K.A. Thole, Experimental validation of large eddy simulations of flow and heat transfer in a stationary ribbed duct, Int. J. Heat Fluid Flow 27 (2006) 243-258

[2] K. Bilen, M. Cetin, H. Gul, T. Balta, The investigation of groove geometry effect on heat transfer for internally grooved tubes, Appl. Thermal Eng. 29 (2009) 753-76

[3] T. Chompookham, C. Thianpong, S. Kwankaomeng, P. Promvonge, Heat transfer augmentation in a wedgeribbed channel using winglet vortex generators, Int. Commu. Heat Mass Transfer 37 (2010) 163-169

[4] S. Sripattanapipat, P. Promvonge, Numerical analysis of laminar heat transfer in a channel with diamond-shaped baffles, Int. Commu. Heat Mass Transfer 36 (2009) 32-38

[5] L. Wang, B. Sunden, Experimental investigation of local heat transfer in a square duct with various-shaped ribs, Heat Mass Transfer 43 (2007) 759-766

[6] J.C. Han, Y.M. Zhang, C.P. Lee, Augmented heat transfer in square channels with parallel, crossed and V-shaped angled ribs, ASME J. Heat Transfer 113 (1991) 590-596

[7] J.C. Han, Y.M. Zhang, C.P. Lee, Influence of surface heat flux ratio on heat transfer augmentation in square channels with parallel, crossed, and V-shaped angled ribs, SME J. Turbomachinery 114 (1992) 872-880

[8] G. Xie, J. Liu, P.M. Ligrani, B. Sunden, Flow structure and heat transfer in a square passage with offset midtruncated ribs, Int. J. Heat Mass Transfer 71 (2014) 4456

[9] B. Facchini, L. Innocenti, M. Surace, Design criteria for ribbed channels: Experimental investigation and theoretical analysis, Int. J. Heat Mass Transfer 49 (2006) 31303141
[10] H. Iacovides, G. Kelemenis, M. Raisee, Flow and heat transfer in straight cooling passages with inclined ribs on opposite walls: an experimental and computational study, Experimental Thermal and Fluid Science 27 (2003) 283294

[11] Ya.I. Smulsky, V.I. Terekhov, N.I. Yarygina, Heat Transfer in turbulent separated flow behind a rib on the surface of square channel at different orientation angles relative to flow direction, Int. J. Heat Mass Transfer 55 (2012) 726-733

[12] C. Mucignat, A. Armellini, L. Casarsa, Flow field analysis inside a gas turbine trailing edge cooling channel under static and rotating conditions: Effect of ribs, Int. J. Heat Fluid Flow 42 (2013) 236-250

[13] G. Tanda, Effect of rib spacing on heat transfer and friction in a rectangular channel with $45^{\circ}$ angled rib turbulators on one/two walls, Int. J. Heat Mass Transfer 54 (2011) 1081-1090

[14] M.A. Moon, M.J. Park, K.Y. Kim, Evaluation of heat transfer performances of various rib shapes, Int. J. Heat Mass Transfer 71 (2014) 275-284

[15] J.H. Wagner, B.V. Johnson, B.A. Graziani, F.C. Yeh, Heat transfer in rotating serpentine passages with trips normal to the flow, ASME J. Turbomachine 114 (1992) 847-857

[16] B.V. Johnson, J.H. Wagner, G.D. Steuber, F.C. Yeh, Heat transfer in rotating serpentine passages with trip skewed to the flow, ASME Turbomachine 116 (1994) 113123

[17] F.P. Incropera, D.P. DeWitt, Fundamentals of Heat and Mass Transfer, fifth edition 2002, John Wiley \& Sons, New York

[18] J.S. Lee, J. Ahn, Large eddy simulation of flow and heat transfer in a channel with a detached rib array, Int. J. Heat Mass Transfer 53 (2010) 445-452

[19] D.K. Tafti, Evaluating the role of subgrid stress modeling in a ribbed duct for the internal cooling of turbine blades, Int. J. Heat Fluid Flow 26 (2005) 92-104 